\title{
Rekayasa Budaya dan Dinamika Sosial: Menemukan Pokok Pikiran Lokalitas Budaya Sebagai Daya Cipta
}

\author{
Erond Litno Damanik \\ Program Studi Pendidikan Antropologi, Fakultas Ilmu Sosial \\ Universitas Negeri Medan, Indonesia
}

Diterima: Desember 2018; Disetujui: Desember 2018; Dipublish: Desember 2018

E-mail: eronddamanik@yahoo.com

\begin{abstract}
Abstrak
Tulisan ini mendiskusikan tentang rekayasa budaya terhadap dinamika sosial, yaitu kebudayaan sebagai daya cipta menghadapi perubahan sosial. Pada tulisan ini, dinamika sosial merupakan respon kreatif dari masyarakat pendukung kebudayaan yang berasal dari ide yang kemudian tersalur pada aktifitas serta menampak pada artefak manusia. Dinamika sosial tidak selamanya didukung institusi formal tetapi juga disokong institusi informal yakni budaya yang sangat berperan aktif. Ide yakni muasal aktifitas dan artefak pada kebudayaan adalah cara berfikir yakni respon kreatif pada daya cipta. Adapun masalah dalam kajian ini adalah benarkah kebudayaan dapat direkayasa menjadi daya cipta?. Hasil kajian menunjukkan bahwa kebudayaan dapat direkayasa menjadi daya cipta sebagai agen dinamika sosial dengan cara: (i) mencatat dan menyaring pokok-pokok pikiran lokalitas budaya, (ii) merumuskan dan mendesain strategi pengembangan lokalitas budaya, (iii) membangun pranta-pranata lokalitas budaya, (iv) menyebarkanluaskan dan menanamkan inti pikiran lokalitas budaya, (v) membuat regulasi melindungi inti pikiran lokalitas budaya, dan (vi) menerapkan hal-hal pokok lokalitas budaya sebagai agen dinamika sosial.
\end{abstract}

Kata Kunci: Pokok Pikiran, Rekayasa, Dinamika Sosial, Lokalitas Budaya, Target Perubahan.

\begin{abstract}
This paper discusses cultural engineering on social dynamics, namely culture as the creativity of facing social change. In this paper, social dynamics is a creative response from the culture support community that originates from ideas which are then channeled into activities and appear in human artifacts. Social dynamics are not always supported by formal institutions but are also supported by informal institutions, namely cultures that play an active role. The idea that the origin of activities and artifacts in culture is a way of thinking that is a creative response to creativity. As for the problem in this study, is it true that culture can be engineered into creativity? The results of the study show that culture can be engineered as a creative power as an agent of social dynamics by: (i) recording and filtering out the thoughts of cultural locality, (ii) formulating and designing strategies for developing locality culture, (iii) building cultural locality pranata, (iv) disseminating and instilling the core of cultural locality, (v) making regulations protect the core thoughts of cultural locality, and (vi) applying basic things to cultural locality as agents of social dynamics.
\end{abstract}

Keywords: Principles of Mind, Engineering, Social Dynamics, Cultural Locality, Target Change.

How to Cite: Damanik. E. L (2018). Rekayasa Budaya dan Dinamika Sosial: Menemukan Pokok Pikiran Lokalitas Budaya sebagai Daya Cipta. Journal of Education, Humaniora and Social Sciences (JEHSS). 1 (2): 93-104.

\section{PENDAHULUAN}

Relasi antara kebudayaan dan dinamika sosial terfokus pada dua hal yakni (i) agen dinamika, dan (ii) target dinamika itu sendiri. Menyoal yang disebut pertama, kebudayaan mengandung simbol dan aksi yang mampu mereproduksi materil serta memiliki kemampuan untuk mendorong individu/kelompok merekonstruksi struktur dan lingkungan materil sesuai respon kreatifnya (Greif, 2006) (Greif, 1994; Barro dan McCleary, 2003). Sedangkan menyoal yang disebut kedua, kebudayaan harus dirubah karena seringkali menjadi penghambat dinamika sosial (Xing, 2001). Menurut van Peursen (1988) kebudayaan adalah manifestasi seluruh aspek kehidupan setiap orang dan kelompok orang yang berkembang dari tahap mitis, ontologis dan 
fungsional. Menurut van Peursen (1988) hal pokok kebudayaan bukanlah budaya itu sendiri melainkan strategi yang terkandung dan tampak pada how survival is the nation.

Sejalan dengan pernyataan ini, ketertinggalan budaya misalnya terletak pada kecepatan respon kreatif terhadap dinamika sosial. Pada skope yang lebih luas, keterbelakangan ataupun kemiskinan sangat terkait dengan kegagalan cara-cara berfikir ataupun kegagalan mengadaptasikan diri dengan dinamika yang terjadi. Dalam hal ini, kegagalan pemajuan kebudayaan merembes pada ketertinggalan berbagai aspek seperti ekonomi, politik, sosial termasuk kebudayaan itu sendiri. Ketertinggalan seperti ini mengakar dari sistem ide (gagasan atau prakarsa) yang ada dalam kepala the idols of culture. Penting diketahui bahwa dinamika sosial tidak selalu harus ditopang dengan kehadiran institusi formal. Namun, dinamika itu harus ditopang kemunculan institusi informal yakni cara-cara kreatif ataupun cara pikir kreatif yang terkandung pada kebudayaan (Hennida dkk, 2008). Untuk itu, kebudayaan menjadi agen dinamika sekaligus menjadi target dinamika. Dalam hal ini, baik sebagai agen maupun target dinamika, maka kebudayaan harus mendapat perlakuan berupa perekayasaan (modifable) sehingga dapat diandalkan menjadi instrumen dinamika itu sendiri.

Sejumlah hasil riset menunjukkan keterkaitan erat kebudayaan dan dinamika sosial pada berbagai masyarakat di dunia. Keterkaitan dimaksud terdapat pada aspek pembangunan seperti platform ekonomi (Muller, 2013; Guiso et al, 2006; Weber, 2001; Bellah, 1992; Abdullah, 1979; Dove, 1988; Evers, 1984), platform pembangunan desa (Chambers, 1987; ), platform politik (Almond dan Verba, 1990; Hale, 2008; Anderson, 2000), platform karakter (Lickona, 1992; Heryanto, 2000; Huizinga, 1900), platform kekuasaan (Said, 1995), platform kepemimpinan (Antlov, 2001; Sartono, 1984; Nordholt, 1987), dan lain-lain. Mengetahui peran kebudayaan dalam setiap aspek dinamika sosial, maka kajian-kajian tentang kebudayaan itupun tumbuh mekar di Indonesia (Suseno, 1984; Abdullah, 1994; 2002; Alfian, 1982; Castels, 1967; de Jonge, 1989; Evers, 1994; Sairin, 1991; Geertz, 1973; 2000; Kuntowijoyo, 1987; Soedjatmoko, 1987; Danandjaja, 1984; Mulyana dan Rakhmat, 2002), platform pemajuan pertanian (Geertz, 1976; Popkins, 1986) dan lain-lain. Namun demikian, peran kebudayaan dalam pembangunan di Indonesia masih tampak kurang nyata. Kajiankajian yang ada itu masih sebatas laporan riset yang terendap di perpustakaan dan belum dimanfaatkan sebagai instrumen dinamika sosial. Ironisnya, terhadap impor teori modernisasi di tahun 1970-an, Koentjaraningrat (2000) justru mengkritisinya karena dinilai tidak mengakar pada culture Indonesia.

Barangkali, suatu contoh hasil kajian perbandingan kebudayaan yang patut ditiru dan dikembangkan adalah merantau pada orang Minangkabau (Naim, 1979) dan Mandailing (Pelly, 2013). Dikatakan bahwa, keputusan merantau pada dua etnik ini tidak semata-mata dipengaruhi full and push factor tetapi sangat tergantung pada 'misi budaya' (culture mission). Namun, kekayaan yang didapat orang Minangkabau di tanah rantau disalurkan kembali ke kampung halaman sedangkan kekayaan merantau bagi orang Mandailing justru memperluas harajaon di tanah rantau. Itulah sebabnya, Gebu Minang sebagai sebuah gerakan pembangunan kultural di tanah Minangkabau sangat berhasil, sedangkan Marsipature Hutana Be (MHB) kurang berhasil di Sumatera Utara. Sama halnya dengan etnik Toba yang sangat gemar meninggalkan kampung halaman (bona pasogit) dan mencari penghidupan yang lebih layak di tanah rantau (bona ni ranto) (Cunningham, 1958; Hasselgren, 2008; Nainggolan, 2012). Misi budaya yang melatari migrasi etnik Toba ini mengakar dalam falsafah budaya mereka yakni hamoraon (kekayaan), hagabeon (memiliki keturunan), dan hasangapon (kehormatan). Meskipun, falsafah budaya ini mampu menghantarkan keberhasilan individu bagi etnik Toba, tetapi kurang berkontribusi bagi bona pasogit. Jikapun ada misalnya, maka yang pantas disebut hanyalah beberapa nama saja seperti T.B. Silalahi ataupun L.B. Panjaitan.

Di Simalungun lain lagi. Pada etnik ini terdapat falsafah budaya yakni Habonaron do Bona $(H d B)$ yakni 'kebenaran adalah pangkal segalanya'. Falsafah ini terangkum dari manuskripmanuskrip kuno Simalungun seperti: Parpandanan na Bolag, Parmongmong Bandar Sahuda, Hikayat Malasori, Partikkian Bandar Hanopan, Hikayat Partiga-tiga Sipunjung, foklore si Jonaha dan lain-lain (Damanik, 2017a). Manuskrip yang berisikan pengobatan tradisional, sejarah asal usul, penanggalan, kosmogoni dan kosmologi ini menjadi catatan penting tentang tradisi kelampauan Simalungun sekaligus sumber tertulis tentang religi aslinya yakni 'habonaron'. HdB 
merupakan virus sukses bagi masyarakat pendukungnya dengan mengedepankan habonaron pada setiap aspek kehidupan (Damanik, 2017b).

Kebudayaan memiliki nilai-nilai (value) dan makna (meaning) yang diwariskan, ditafsirkan dan diimplikasikan pada proses dinamika sosial dan kultural masyarakat. Antropolog Geertz (1973) menggariskan bahwa kebudayaan merupakan pola dari pengertian-pengertian atau makna yang terjalin secara menyeluruh dalam simbol-simbol yang ditransmisikan secara historis, suatu sistem mengenai konsepsi-konsepsi yang diwariskan dalam bentuk-bentuk simbolik yang dengan cara tersebut manusia berkomunikasi, melestarikan dan mengembangkan pengetahuan dan sikap mereka terhadap kehidupan. Jadi, nilai dan makna yang terkandung dalam kebudayaan terimplikasi dan terintegrasi dalam hidup manusia sehari-hari dalam menjawab tantangan hidup.

Pengintegrasian nilai dan makna kebudayaan dalam kehidupan sehari-hari menjadi pelegitimasian kebudayaan dalam kehidupan masyarakat. Pada bagian ini, kebudayaan tidak dimaknai sebagai sesuatu yang ancient semata, tetapi terutama menjadi bagian dalam dinamika sosial, yaitu sebagai agenda daya cipta. Sarjana seperti Kluckhohn dan Strodtbeck (1961) telah menggariskan bahwa kebudayaan memiliki orientasi nilai tertinggi pada lima hal yakni: (i) human nature, (ii) man nature, (iii) time, (iv) activity, dan (v) relational. Kelima orientasi manusia tersebut berasal dari pola-pola kebudayaan (patterns of culture) yang menurut Benedict (1946) menjadi dasar sekaligus perangkat nilai pembentuk panduan yang fundamental bagi manusia. Jadi, pemajuan kebudayaan ialah merumuskan dan menjadikan pokok-pokok pikiran sebagai strategi pada dinamika sosial sekaligus sebagai instrumen memberi arah pada dinamika sosial yang bakal terjadi. Guna merespon perubahan dimaksud, maka kebudayaan memerlukan rekayasa (modifable).

Tulisan ini bermaksud mendiskusikan perekayasaan budaya dalam sebagai agenda daya cipta dan instrumen dinamika sosial. Adapun permasalahan dalam kajian ini adalah: benarkah kebudayaan dapat direkayasa sebagai agenda daya cipta yakni instrumen dinamika sosial pada masyarakat?. Perekayasaan kebudayaan mengacu pada orientasi nilai tertinggi kebudayaan sebagaimana digariskan Kluckhon dan Strodtbeck (1961) yakni orientasi kebudayaan terhadap manusia, alam dan lingkungan, waktu, aktifitas (kerja) dan keterikatan sosial. Dengan kata lain, kebudayaan menjadi embrio lahirnya platform pembangunan, ekonomi, politik, etika (karakter), kepemimpinan, organisasi sosial dan etos kerja. Sebagaimana disebut Surbakti (2018), pemajuan kebudayaan daerah diberi ruang luas pada politik lokal pada era desentralisasi sejak tahun 1998.

\section{METODE PENELITIAN}

Kajian ini dilakukan secara kualitatif dengan pendekatan hermenetik yakni melihat kebudayaan sebagai teks-teks yang harus dibaca, ditransliterasi dan diinterpretasikan. Menurut Geertz (1973) kebudayaan adalah suatu teks yang perlu diinterpretasikan maknanya daripada sebagai suatu pola perilaku yang sifatnya kongkrit. Metode ini disebut dengan Tafsir Kebudayaan (interpretation of culture). Mengacu pada metode ini kebudayaan adalah pendefenisian manusia terhadap dunianya, menyatakan perasaannya dan memberikan penilaiannya yakni suatu pola yang ditransmisi dan diwujudkan dalam bentuk simbolik melalui pengetahuan dan sikap dalam hidupnya. Dalam hal ini, kebudayaan dilihat sebagai jaringan makna simbol yang dalam penafsirannya perlu dilakukan pendeskripsian mendalam (thick description). Pada kajian ini, objek yang ditelaah adalah manuskrip di Simalungun guna menemukan konsep pembangunan yang relevan dengan orang Simalungun menghadapi Abad 21. Telaah terhadap manuskrip ialah pokok-pokok pikiran (core of culture) yang direkayasa menjadi model menghadapi dinamika sosial.

\section{HASIL DAN PEMBAHASAN}

Merumuskan pokok-pokok pikiran, strategi dan rencana induk pemajuan kebudayaan

Wujud 'Ide' dalam kebudayaan adalah budaya benda maupun budaya tak benda. Budaya benda dan tak benda adalah lingkup aktifitas dan artefaktual yang mendapatkan pelestarian 议 $\mathrm{w}$ http://mahesainstitute.web.id/ojs2/index.php/jehss (1.) mahesainstitut@gmail.com 
(pelindungan, pengembangan dan kemanfaatan). Di Indonesia, budaya benda telah diatur dengan UU no. 11 Tahun 2010 tentang Cagar Budaya yang objeknya terdiri dari (i) benda, (ii) bangunan, (iii) situs, (iv) struktur dan (v) kawasan Cagar Budaya. Sedangkan budaya tak benda diatur dengan UU no. 5 Tahun 2017 tentang Pemajuan Kebudayaan yang objeknya terdiri dari: (i) tradisi lisan, (ii) manuskrip, (iii) adat istiadat, (iv) ritus, (v) pengetahuan tradisional, (vi) teknologi tradisional, (vii) seni, (viii) bahasa, (ix) permainan rakyat, dan (x) olahraga tradisional. Kedua UU ini sangat technical dan taktis guna 'pelestarian' kebudayaan benda maupun tidak benda memuat: (i) pelindungan, (ii) pengembangan, dan (iii) kemamfaatan. Institusi khusus negara yang mewadahi budaya benda adalah Balai Arkeologi (Balar) maupun Balai Pelestarian Cagar Budaya (BPCB) sedangkan mewadahi budaya tak benda adalah Balai Pelestarian Nilai Budaya (BPNB). Namun keterbatasan yang dimilikinya menjadi salah satu penghambat pelestarian kebudayaan di Indonesia.

Perlu dicatat bahwa pelestarian kebudayaan benda atau cagar budaya tidaklah serumit kebudayaan tak benda karena objeknya bersifat kongkrit. Pemjauan Kebudayaan tidak benda yang bersifat abstrak (10 objek) dimajukan dengan mengambil pokok-pokok pikiran. Pokok pikiran ini adalah abstraksi yang memuat makna (meaning) dan nilai (value) yang terikat oleh sistem norma (norm system). Kemudian, pokok-pokok pikiran dirancang melalui strategi pemajuan yang kemudian dituangkan dalam Rencana Induk Pemajuan Kebudayaan (RIPK) secara berkala.

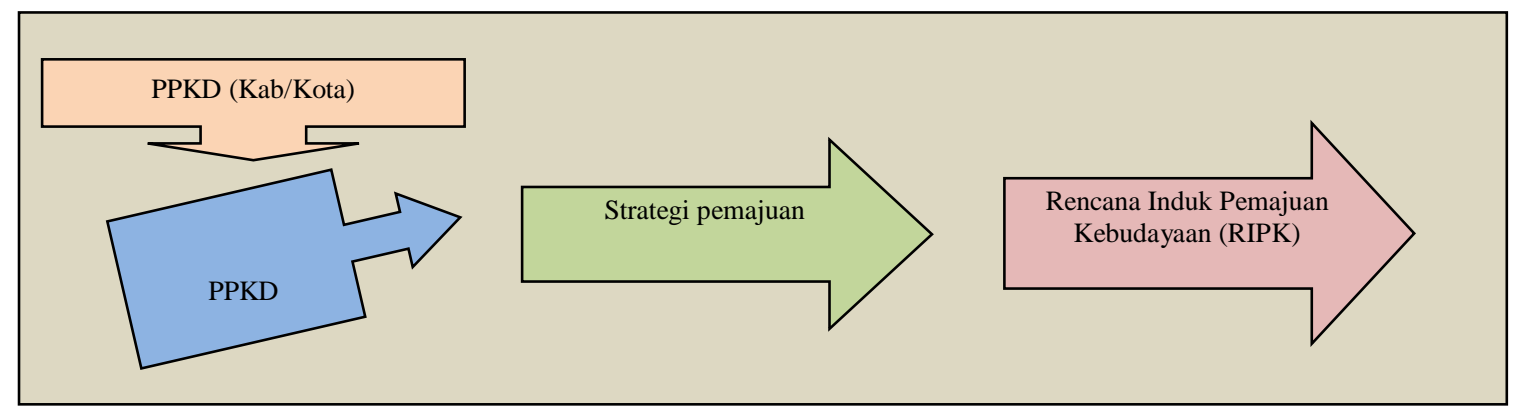

Langkah-langkah perumusan Pokok-pokok Pikiran Kebudayaan (sesuai pasal 11 ayat (2) UU no. 5 Tahun 2017), penyusunan Strategi pemajuan (sesuai pasal 13 ayat (2) UU no. 5 Tahun 2017) dan penyusunan Rencana Induk Pemajuan Kebudayaan (sesuai pasal 14 ayat (2) UU no. 5 Tahun 2017) adalah sebagaimana tampak pada tabel berikut:

Tabel 1. Komponen pokok pikiran, strategi dan rencana induk Pemajuan Kebudayaan

\begin{tabular}{|c|c|c|}
\hline Perumusan Pokok Pikiran & Penyusunan Strategi & Penyusunan RIPK \\
\hline $\begin{array}{l}\text { Identifikasi keadaan terkini dari } \\
\text { perkembangan Objek Pemajuan } \\
\text { Kebudayaan. } \\
\text { Identifikasi Sumber Daya Manusia } \\
\text { Kebudayaan, lembaga Kebudayaan, } \\
\text { dan pranata Kebudayaan. } \\
\text { Identifikasi sarana dan prasarana } \\
\text { Kebudayaan. } \\
\text { Identifikasi potensi masalah } \\
\text { Pemajuan Kebudayaan. } \\
\text { Analisis dan rekomendasi untuk } \\
\text { implementasi } \\
\text { Kebudayaan }\end{array}$ & $\begin{array}{l}\text { Abstrak dari dokumen Pokok } \\
\text { Pikiran Kebudayaan. } \\
\text { Visi Pemajuan Kebudayaan } 20 \text { (dua } \\
\text { puluh) tahun ke depan. } \\
\text { Isu strategis yang menjadi skala } \\
\text { prioritas untuk mempercepat } \\
\text { pencapaian visi. } \\
\text { Rumusan proses dan metode utama } \\
\text { pelaksanaan } \\
\text { Kebudayaan. }\end{array}$ & $\begin{array}{l}\text { Visi dan misi Pemajuan } \\
\text { Kebudayaan. } \\
\text { Tujuan dan sasaran. } \\
\text { Perencanaan. } \\
\text { Pembagian wewenang. } \\
\text { Alat ukur capaian }\end{array}$ \\
\hline $\begin{array}{lcc}\text { Disusun } & \text { oleh } & \text { Daerah } \\
\text { Kabupaten/Kota/Provinsi } & \\
\end{array}$ & $\begin{array}{ll}\text { Disusun } & \text { Pemerintah } \\
\text { melibatkan Tenaga Ahli }\end{array}$ & $\begin{array}{l}\text { Disusun Menteri/Kementerian } \\
\text { dan Lembaga Terkait }\end{array}$ \\
\hline
\end{tabular}

Pemajuan Kebudayaan berpedoman pada prinsip pelestarian kebudayaan (sesuai pasal

16-40 UU no. 5 Tahun 2017) mencakup (i) pelindungan yang terdiri dari: (a) invetarisasi, (b) pengamanan, (c) pemeliharaan, (d) penyelamatan, dan (e) publikasi. Sedangkan konsep (ii) pengembangan dan terakhir (iii) pemanfaatan dan pembinaan. 
Tabel 2. Komponen dan Sub-komponen Pemajuan Kebudayaan

\begin{tabular}{|c|c|c|}
\hline Komponen & $\begin{array}{l}\text { Sub- } \\
\text { komponen }\end{array}$ & Uraian aktifitas \\
\hline \multirow{5}{*}{ Pelindungan } & Inventarisasi & $\begin{array}{l}\text { Pencatatan pendokumentasian, } \\
\text { Penetapan } \\
\text { Pemutakhiran data. }\end{array}$ \\
\hline & Pengamanan & $\begin{array}{l}\text { Pemutakhiran dalam Sistem Pendataan Kebudayaan Terpadu } \\
\text { Mewariskan Objek Pemajuan Kebudayaan antar generasi. } \\
\text { Memperjuangkan Objek Pemajuan Kebudayaan sebagai warisan budaya } \\
\text { dunia. }\end{array}$ \\
\hline & Pemeliharaan & $\begin{array}{l}\text { Menjaga nilai keluhuran dan kearifan Objek Pemajuan Kebudayaan. } \\
\text { Menggunakan Objek Pemajuan Kebudayaan dalam kehidupan sehari- } \\
\text { hari. } \\
\text { menjaga keanekaragaman Objek Pemajuan Kebudayaan. } \\
\text { Menghidupkan dan menjaga ekosistem Kebudayaan untuk setiap Objek } \\
\text { Pemajuan Kebudayaan. } \\
\text { Mewariskan Objek Pemajuan Kebudayaan kepada generasi berikutnya. }\end{array}$ \\
\hline & Penyelamatan & $\begin{array}{l}\text { Revitalisasi. } \\
\text { Repatriasi. } \\
\text { Restorasi. }\end{array}$ \\
\hline & Publikasi & $\begin{array}{l}\text { Penyebaran informasi kepada publik baik di dalam negeri maupun di } \\
\text { luar negeri dengan menggunakan berbagai bentuk media. }\end{array}$ \\
\hline Pengembangan & $\begin{array}{l}\text { Penyebarluasan. } \\
\text { Pengkajian. } \\
\text { Pengayaan keber: }\end{array}$ & gaman. \\
\hline \multirow{2}{*}{ Pemanfaatan } & Tujuan & $\begin{array}{l}\text { Membangun karakter bangsa. } \\
\text { Meningkatkan ketahanan budaya. } \\
\text { Meningkatkan kesejahteraan masyarakat. } \\
\text { Meningkatkan peran aktif dan pengaruh Indonesia dalam hubungan } \\
\text { internasional. }\end{array}$ \\
\hline & Mekanisme & $\begin{array}{l}\text { Internalisasi nilai budaya. } \\
\text { Inovasi. } \\
\text { Peningkatan adaptasi menghadapi perubahan. } \\
\text { Komunikasi lintasbudaya. } \\
\text { Kolaborasi antarbudaya. }\end{array}$ \\
\hline Pembinaan & \multicolumn{2}{|c|}{$\begin{array}{l}\text { Peningkatan pendidikan dan pelatihan di bidang Kebudayaan. } \\
\text { Standardisasi dan sertifikasi Sumber Daya Manusia Kebudayaan sesuai dengan kebutuhan } \\
\text { dan tuntutan. } \\
\text { Peningkatan kapasitas tata kelola lembaga Kebudayaan dan pranata Kebudayaan. }\end{array}$} \\
\hline
\end{tabular}

\section{Rekayasa Budaya Sebagai Daya Cipta}

Dunia saat ini bergerak dengan cepat akibat revolusi 4.T yakni technology, telecomunication, transportation, dan tourism. Pada gilirannya, revolusi yang memiliki globalizing force berdampak pada mengaburnya batas antarwilayah sehingga tercipta global village (Saptadi 2008). Pengaruh globalisasi ini berdampak pada memudarnya budaya daerah. Karena itu, guna memperkuat budaya (daerah) sebagai komponen lokalitas diperlukan strategi-strategi pemerkuatan kebudayaan itu sendiri. Penulis Mubah (2011) mengidentifikasi strategi dimaksud mencakup: (i) developing nation identity, (ii) understanding cultural identity, (iii) regulating act to protect local culture, dan (iv) using information technology such as internet to introduce local culture in the globe.

Pemerkuatan lokalitas budaya berguna pada konsep 'pelestarian' bagi kesejahteraan masyarakat dan bukan sekedar 'terlindungi' saja. Harus dicatat bahwa, suatu lokalitas budaya akan menempel pada diri manusia apabila kebudayaan itu masih memiliki kebermanfaatan nyata bagi pendukungnya. Jadi, perlu dipahami bahwa pokok-pokok pikiran kebudayaan adalah abstraksi kebudayaan (jika mengacu pada UU no. 5 Tahun 2017 tentang Pemajuan Kebudayaan 
terdapat 10 objek pemajuan) yang pada konsep ketiga dari 'pelestarian' dimaksudkan untuk memberikan manfaat bagi masyarakat itu sendiri.

Kebudayaan diartikan sebagai kebiasaan, kepercayaan dan nilai-nilai yang dianut kelompok yang cenderung tidak berubah antar generasi yang memandu masyarakat pendukungnya dalam kehidupan sehari-harinya (Guiso et al, 2006). Kebudayaan terinternalisasi dalam kehidupan manusia berupa ide, aktifitas dan artefak. Ketiga wujud kebudayaan ini berada di dalam kepala yakni ide yang terealisasi dalam aktifitas dan artefak pendukungnya. Ide direalisasikan menjadi budaya benda (tangible culture) maupun tak benda (intangible culture). Karena itu, elemen terpenting dari kebudayaan ialah ide, gagasan atau prakarsa yang terlihat pada aktifitas dan artefaktualnya. Karena itu, hal ihwal (origin) terletak pada 'ide' dan menjadi (become) 'aktifitas' serta 'artefak'. Ini berarti bahwa, kebudayaan adalah daya cipta yakni segala sesuatu yang direncanakan dalam kepala manusia pemilik kebudayaan itu. Karenanya, berbicara tentang daya cipta manusia Indonesia sesungguhnya harus mencarinya kembali di akar-akar budayanya sendiri.

Hasil riset Hennida dkk (2008) menegaskan tentang adanya rekayasa fitur-fitur budaya pada pembangunan ekonomi di negara Jepang, Korea Selatan dan Tiongkok lewat proses humiliation $^{l}$ seperti fukoku kyohei, wakon yosai, datsua nyuo, bunmei di Jepang, han, family law dan hallyu di Korea Selatan dan pragmatisme serta sosialisme di Tiongkok. Fitur-fitur budaya dalam pembentukan karakter lewat pendidikan juga tidak terlepas dari akar-akar kebudayaan. Kebudayaan menjadi embrio karakter (etika) pada masyarakatnya yang diwariskan secara terus menerus. Karakter ini ditemukan dari fitur-fitur budaya dan dikembangkan serta ditonjolkan secara universal dalam masyarakat pendukungnya. Karakter dimaksud adalah 'moral' yang menurut Lickona (1992) terbagi dalam tiga kategori yakni: (i) moral knowing, (ii) moral feeling dan, (iii) moral action. Ketiga moral ini terangkum dalam bagan seperti berikut:

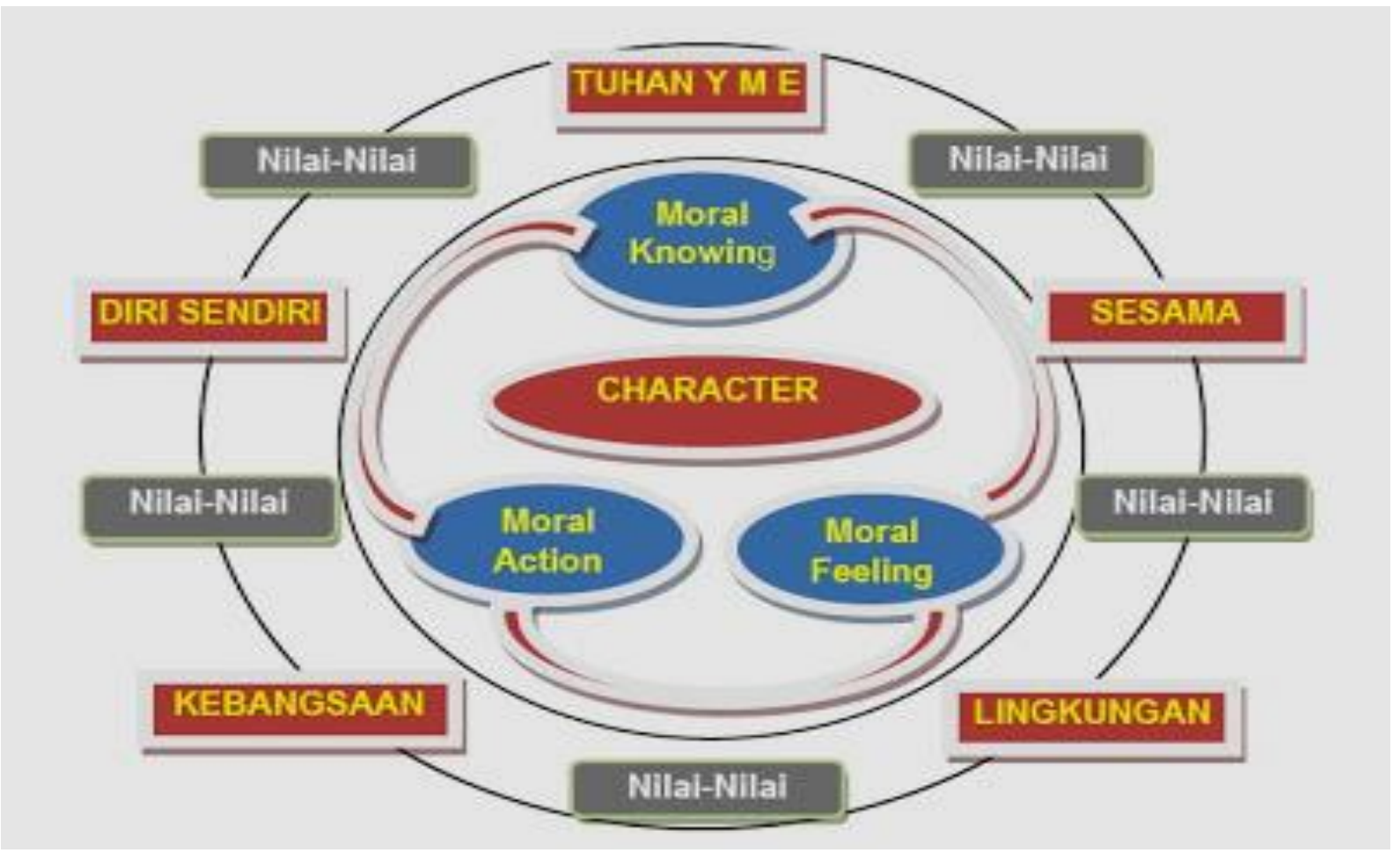

Gambar 1. Skema Lickona tentang keterkaitan karakter dan moral

${ }^{1}$ Humiliation adalah proses mendisiplinkan perilaku pihak-pihak yang merasa dipermalukan dengan cara menyerang dan merendahkan persepsi dirinya (self) dan meninggikan persepsi akan orang lain (others) sebagai lebih baik. Lihat Pual Saurette (2006). "You Dissin Me? Humiliation and Post 9/11 Global Politics", Review of International Studies, 32(3):495-522. 
Pada masyarakat Simalungun seperti disebut Damanik (2017b), moralitas yang terbentuk dari Habonaron do Bona ( $H d B$ ) menjadi dasar pengetahuan, perilaku (tindakan) dan merasa. Dari HdB itu terbentuk fitur budaya yakni 'ahap' (rasa atau sense of belonging). Etika moral ini lahir dari persinggungan identitas budaya dan agama yang bersifat universal. Fitur ahap menjadi etika moral pergaulan, interaksi sesama, dan komunikasi sosial yang tidak memandang identitas (suku, agama, klan, teritorial, ras). Sedangkan dalam dinamika sosial, fitur 'ahap' melahirkan fitur budaya berupa 'haroan bolon' (gotongroyong) dan 'sapangambei manoktok hitei' (kolektifitas) dalam mencapai tujuan bersama. Di dalam fitur-fitur budaya seperti ini terdapat nilai-nilai sosial kolektif yang membentuk sistem norma yang tampak pada kognisi, afeksi dan psikomotorik. Itulah sebabnya, salah satu karakter orang Simalungun adalah kehati-hatian (waspada) karena takut salah dalam bertindak, berucap, berperilaku maupun berfikir, tetapi tegas dan berani dalam memperjuangkan sesuatu hal.
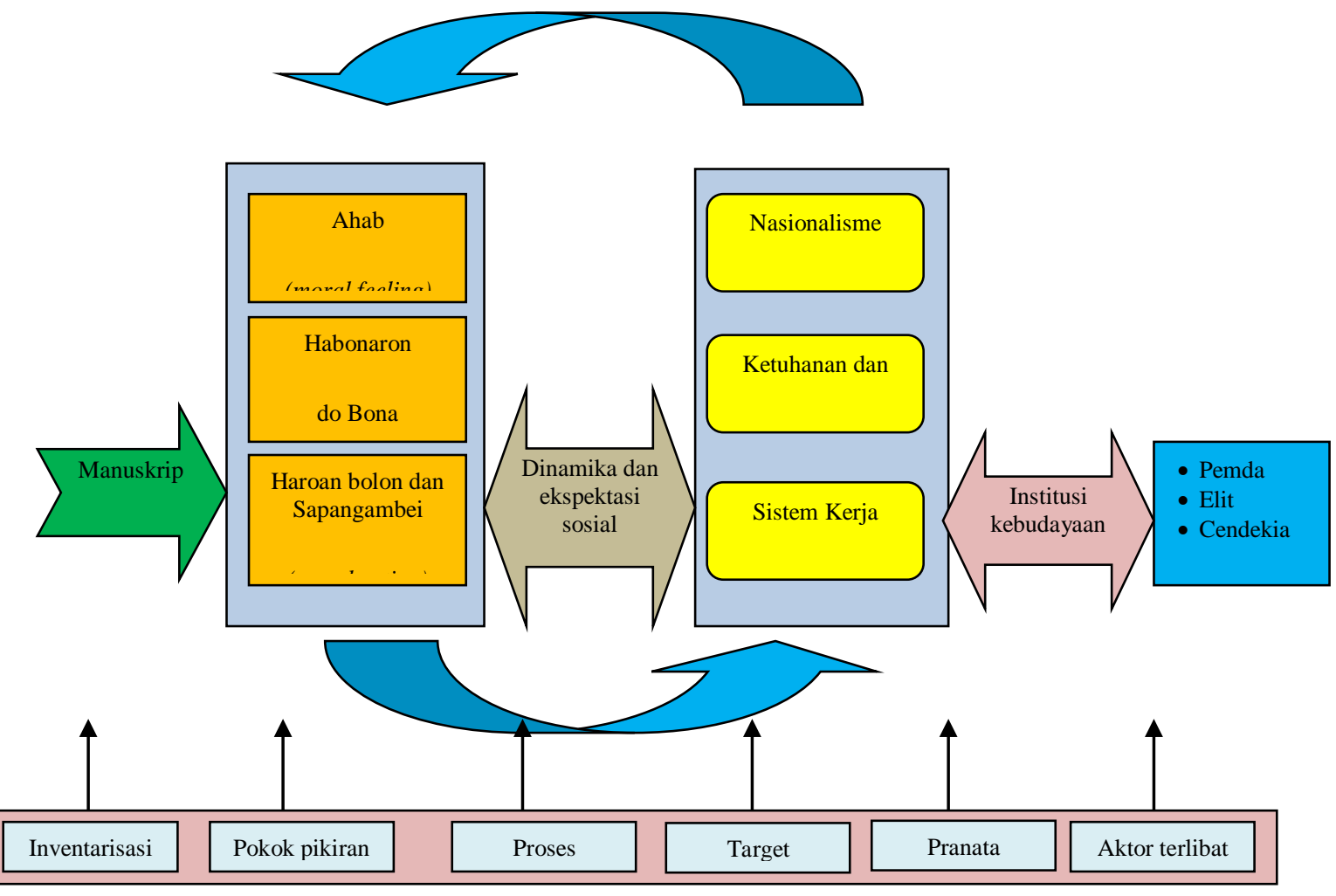

\section{Gambar 2. Skema rekayasa pokok pikiran bersumber manuskrip di Simalungun}

Hutagalung (2007) menyebutkan fitur-fitur budaya adalah nilai-nilai sosial budaya yang menghasilkan norma (norm) dan tampak pada sikap (attitude), pola pikir dan perilaku. Fiturfitur budaya seperti ini seharusnya dimiliki masyarakat yang sedang membangun dan mereformasi diri. Menurutnya, pengabaian terhadap fitur-fitur budaya universal ini berdampak pada mubajirnya pembangunan atau pembaharuan fisik material seperti tampak di negaranegara underdevelopment. Karena itu, agen-agen perubahan dalam masyarakat yakni elit serta intelektual yakni golongan yang memelopori pembaharuan seharusnya mempraktekkan nilai dan norma budaya yang diperlukan dalam masyarakat modern. Menurut Inkeles (2005) masyarakat modern memiliki ciri-ciri yakni: (a) menerima hal-hal baru dan terbuka untuk perubahan, (b) bersikap demokratis, (c) orientasi masa depan dan menghargai waktu, (d) memiliki perencanaan dan pengorganisasian, (e) percaya diri, (f) perhitungan, (g) menghargai sesama, (h) percaya pada ilmu pengetahuan dan teknologi, dan (i) penghargaan terhadap prestasi dan imbalan yang sesuai. 
Barangkali, cita-cita terbesar dari penemuan fitur-fitur kebudayaan sebagai daya cipta adalah menemukan Need for Achievement ( $n$ Ach) sebagaimana disebut McClelland (1988) yakni motivasi atau dorongan berprestasi. Masyarakat yang memiliki motivasi seperti ini memiliki karakteristik seperti: (i) inovatif, (ii) adanya feedback, (iii) tanggungjawab personal, (iv) persistence, dan (v) menyukai tantangan. Penulis Marzali (2014) menyebut bahwa memajukan kebudayaan adalah pemrograman kebudayaan melalui kebijakan publik yang dapat diubah dan direkayasa (modifable), terukur (measurable) serta termonitor perkembangan dan keberhasilannya.

Suatu hal yang pasti adalah bahwa pemajuan kebudayaan harus mengindahkan signifikansi atau keberartian kebudayaan sebagaimana diuraikan Kluckhohn dan Strodtbeck (1961) yakni: (i) human nature, (ii) man nature, (iii) time, (iv) activity, dan (v) relational. Kelima orientasi kebudayaan ini adalah strategi kebudayaan dalam upaya 'how survival' yang mencakup lingkungan, sesama manusia, waktu, aktifitas (kerja) dan hubungan sosial. Karena itu, semakin melekat kuat pokok-pokok pikiran kebudayaan pada masyarakat maka semakin mudah kebudayaan dimaksud dikembangkan, dimajukan dan dimanfaatkan. Kenyataan ini dapat wujud karena pokok-pokok pikiran kebudayaan dimaksud telah terintegrasi dalam kerangka pemikiran (kepala) setiap idols of culture. Pokok-pokok pikiran tersebut adalah fitur-fitur kebudayaan yang dapat dimanfaatkan sebagai instrumen daya cipta menghadapi dinamika sosial. Pada gilirannya, dinamika sosial katakanlah pada konsep pembangunan ekonomi, politik, sosial, kultural dan lainlain terasa lebih mudah dimanfaatkan karena berasal dari internal masyarakat itu sendiri.

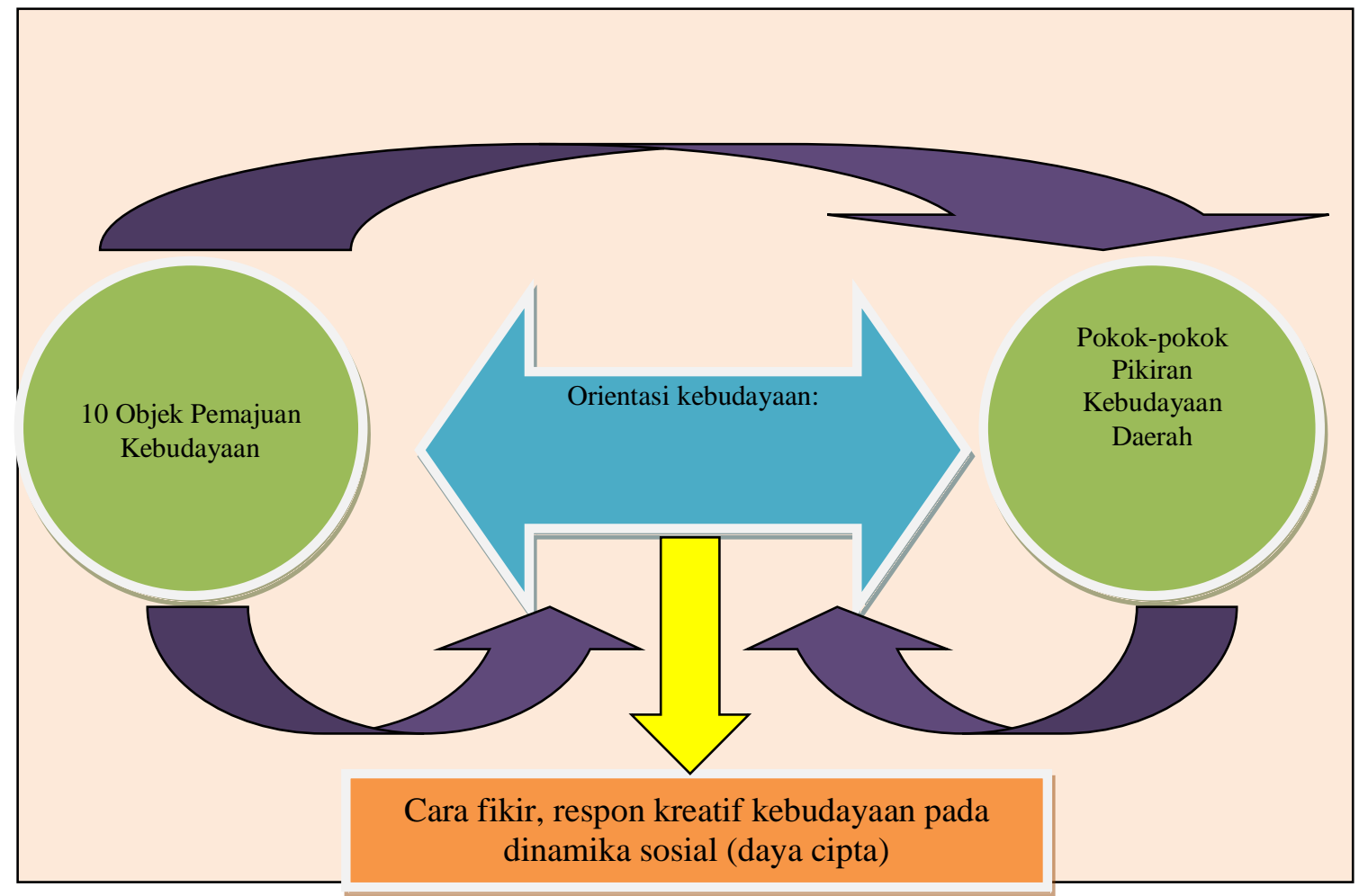

Daya cipta sangat mempengaruhi dinamika sosial. Seperti disebut sebelumnya, di dalam kepala manusia Indonesia terdapat embrio daya cipta (ide, gagasan atau prakarsa) yang berisi cara pikir, respon kreatif dan motivasi beprestasi (need for Achievement). Paling tidak, kenyataan seperti ini dapat terlihat dari 5 kategori objek kebudayaan benda maupun 10 objek kebudayaan tak benda. Masing-masing di dalam objek tersebut terdapat ide (local genius) yang terwujud dalam kearifan (local wisdom), teknologi lokal (local technologi) maupun pengetahuan (local knowledge). Jadi, masing-masing manusia Indonesia memiliki cara-cara berfikir ataupun respon kreatif terhadap dinamika sosial sesuai zamannya. Hanya saja, pemajuan kebudayaan Indonesia bukan saja mengalami stagnasi (jika bukan gradasi) sesuai periodenya, seperti: pertama, Orde Lama memberikan pengakuan terhadap kebudayaan daerah, namun pergolakan yang terjadi 
sepanjang orde dimaksud tidak memungkinkan pemajuan kebudayaan, kedua Orde Baru yang sama sekali tidak memberi ruang berkembangnya budaya daerah selain yang disebut 'Kebudayaan Nasional'. Berbicara tema-tema 'daerah' dianggap subversif dan dianggap mengingkari Nasionalisme Indonesia. Pada saat yang sama, bangsa ini disuguhi 'modernisasi' yang membuka lebar 'Indonesia' bagi seluruh penjuru dunia termasuk budaya luar (budaya populer atau budaya massa). Akibatnya, budaya daerah makin memudar dan sepertinya tidak dapat diandalkan dalam dinamika sosial (sebagai perbandingan lihat Cornelis Lay, 2011), ketiga Orde Reformasi memberi ruang pada pemajuan kebudayaan sejalan dengan penyelenggaraan desentralisasi.

Sebagaimana disebut Surbakti (2018) dalam pendahuluan Politik Lokal karya Damanik (2018) bahwa politik lokal di era desentralisasi tidak saja menyoal politik, ekonomi ataupun penyelenggaraan pemerintahan di daerah, tetapi juga sekaligus berkontribusi dalam pemajuan kebudayaan. Pemajuan kebudayaan ini sekaligus ditujukan pada pengayaan kebhinekaan budaya dan masyarakat di Indonesia. Apresiasi terhadap kebudayaan daerah mulai ditingkatkan kembali melalui penerbitan dua UU (no 11 tahun 2010 maupun no. 5 tahun 2017), tetapi tampaknya masih membutuhkan waktu yang relatif panjang karena masih harus menemukan pokok-pokok pikiran (abstraksi) yang terkandung pada objek kebudayaan dimaksud sebagai daya cipta.

Terakhir, keempat adalah kurangnya apresiasi pemerintah daerah terhadap 'kebudayaan' yang dianggap semata-mata sebagai 'pekerjaan' instansi terkait (kebudayaan, pariwisata maupun pendidikan). Pemajuan kebudayaan dimaknai sekedar 'inventarisasi', 'pencatatan', 'penetapan' dan 'promosi' tanpa menghidupkan, mengembangkan, dan memanfaatkan elemen penting dari kebudayaan yakni 'ide'. Bagaimanapun juga, elemen penting dari kebudayaan adalah 'ide' (karena didalamnya terdapat daya cipta) kemudian terwujud dalam aktifitas dan artefak. Jadi, pemerintah daerah sesuai wilayahnya harus menemukan 'ide-ide' yang terkandung dalam kebudayaan daerah sebagai komponen 'lokalitas budaya' guna menjadikan kebudayaan sebagai basis daya cipta.

\section{SIMPULAN}

Bagian penting dan utama dari kebudayaan tidaklah kebudayaan itu sendiri, tetapi adalah strategi kebudayaan dalam menghadapi dinamika sosial yakni bagaimana bertahan hidup (how survival). Dalam konsep ini, kebudayaan memiliki segenap ide atau gagasan ataupun prakarsa yaitu embrio daya cipta yang termanifestasi dengan aktifitas dan artefak. Karena itu, menjadikan kebudayaan sebagai basis daya cipta sangat penting guna menghasilkan cara-cara pikir mutakhir dan mampu menelurkan respon kreatif yang adaptable terhadap dinamika sosial. Dalam hal ini, rekayasa budaya (modifable culture) dibutuhkan yang melingkupi: (i) mencatat dan menyaring pokok-pokok pikiran lokalitas budaya, (ii) merumuskan dan mendesain strategi pengembangan lokalitas budaya, (iii) membangun pranta-pranata lokalitas budaya, (iv) menyebarkanluaskan dan menanamkan inti pikiran lokalitas budaya, (v) membuat regulasi melindungi inti pikiran lokalitas budaya, dan (vi) menerapkan hal-hal pokok lokalitas budaya sebagai agen dinamika sosial

\section{DAFTAR PUSTAKA}

Greif, A. (2006). Cultural beliefs and the organization pf Society: a historical and theoritical reflection on collectivist and individualist societies. Journal of Economic Perspectives, 20(2), 23-48.

Abdullah, T. (ed.) (1979). Agama, etos kerja dan perkembangan ekonomi. Jakarta: LP3ES.

Abdullah, I. (1994). The Muslim bussinesmen of Jatinom: Religious reform and Economy modernization in a Javanese town. Ph.D dissertation, University of Amsterdam.

_ (2002). Tantangan Pembangunan Ekonomi dan Transformasi Sosial: Suatu Pendekatan Budaya. Humaniora. XIV (2), hal. 260-270.

Almond, G.A. \& Verba, S (1990). Budaya politik: Tingkahlaku politik dan demokrasi di lima negara. Jakarta: Bumi Aksara.

Alfian (1982). Politik, Kebudayaan dan Manusia Indonesia. Jakarta: LP3ES. 
Anderson, B.R.O.G. (2000). Kuasa Kata: Jelajah Budaya-budaya Politik di Indonesia. Yogyakarta: Mata Bangsa.

Barro, R.J. \& McCleary, M.R. (2003). "Religion and Economic Growth”, Working Paper, No. 9682.

Bellah, R.N. (1992). Religi Tokugawa: Akar-akar budaya Jepang. Jakarta: Gramedia Pustaka Utama.

Benedict, R. (1946). Patterns of culture. New York: Pelican book.

Castels, L. (1967). Religion, Politics, and Economic Behaviour in Java: The Kudus Cigarrette Industry. Cultural Report Series No. 15, Yale University.

Cunningham, C.E. (1958). The postwar migration of the Tiba-Bataks to East Sumatera. New Haven: Yale University Southeast Asia

Chambers, R. (1987). Pembangunan desa: mulai dari belakang. Jakarta: LP3ES.

De Jonge, H. (1989). Madura dalam Empat zaman: pedagang, perkembangan ekonomi dan, Islam. Jakarta: Gramedia.

Dove, M.R. (1988). Sistem perladangan di Indonesia: Studi kasus di Kalimantan Barat. Yogyakarta: Gadjah Mada University Press.

Evers, H.D. Clauss, W. \& Wong, D. (1984). Reproduksi subsistensi: Suatu kerangka Analsiis dalam Teori Masyarakat: Proses peradaban dalam sistem dunia modern. Hans Dieter Evers (ed.) Jakarta: Obor Indonesia.

et al. (1994). The Moral Economy of Trade: Ethicity and Developing Markets. London: Routledge.

Danandjaja, J. (1984). Folklore Indonesia: ilmu gossip, dongeng, dan lain-lain. Jakarta: Graffiti Press.

Damanik, E.L. 2017a. Agama, perubahan sosial dan identitas etnik: moralitas agama dan kultural di Simalungun. Medan: Simetri Institute

(ed). 2017b. Habonaron do Bona: tantangan dan refleksi Abad 21. Medan: Simetri Institute.

Geertz, C. (1973). The interpretation of cultures. New York: Basic Books Inc.

_ (2000). Local Knowledge: further Essay in interpretative Anthropology. Perseus Books.

(1976). Involusi pertanian: proses perubahan ekologi di Indonesia. Jakarta: Bharata.

Guiso, L. Sapienza, P. \& Zingales, L (2006). "Does culture affect economic outcomes? Journal of Economic Perspectives, 20(2): 23-48.

Greif, A. (1994). "Cultural beliefs and the organization of society: a historical and theoretical reflection on collectivist and individualist societies", The Journal of Political Economy. 102(5): 912-950.

Hale, H.E. (2008). The Foundations of Ethnic Politics: Separatism of States and Nations in Eurasia and the World. Cambridge: Cambridge University Press.

Hans, A. \& Cederroth, S. (2001). Kepemimpinan Jawa: Perintah Halus, Pemerintahan Otoriter. Jakarta: Obor Indonesia.

Hasselgren, J. (2008). Batak Toba di Medan: perkembangan identitas etnoreligius Batak Toba di Medan, 1912-1965. Medan: Bina Media Perintis.

Heryanto, A. (2000). Perlawanan dalam Kepatuhan: Esai-esai Budaya. Bandung: Mizan

Hennida, C. dkk (2008). Budaya dan Pembangunan Ekonomi di Jepang, Korea Selatan dan China. Global \& Strategies 10 (2), hal. 248-263.

Huizinga, J. (1990). Homo Ludens: Fungsi dan hakekat permainan dalam budaya. Jakarta: LP3ES.

Hutagalung, M.P. (2007). Budaya Malu, Budaya Salah, dan Budaya Hukum, Jurnal Hukum dan Pembangunan, 37 (3), hal. 359-380.

Inkeles, A. (2005) "Modernisasi Manusia" dalam Myron Weiner, (ed.,). Modernisasi: Dinamika Pertumbuhan. Voice of America Forum Lectures.

Kartodirjo, S. (1984). Kepemimpinan dalam dimensi sosial. Jakarta: LP3ES.

Koentjaringrat (2000). Kebudayaan, mentalitas, dan pembangunan. Jakarta: Gramedia Pustaka Utama.

Kuntowijoyo (1987). Budaya dan Masyarakat. Yogyakarta: Kreasi Wacana.

Kluckhohn, F.R. \& Strodtbeck, F.L. (1961). Variations in Value Orentations. Evanston, IL: Row, Peteson.

Lay, C. (2011). "Otonomi Daerah dan ke-Indonesia-an”, dalam Abdul Karim Gaffar (ed.). Kompleksitas Persoalan Otonomi Daerah di Indonesia. Jakarta: Pustaka Pelajar.

Lickona, T. (1992). Educating for Character: How our schools can teach, respect and responsibility. New York: Bantam Books.

Marzali, A. (2014) Memajukan Kebudayaan Nasional Indonesia, Humaniora 26 (3), hal. 251-265.

Muller, M. (2013). Kebudayaan dan Perkembangan Ekonomi: Suatu penelitian empiris lingkungan budaya dan kemampuan-kemampuan wiraswasta di Tanah Papua, Indonesia (Nugini Barat). Marburg: Disertasi, Philipps-Universiteit.

Mulyana, D. \& Rakhmat, J (2002). Komunikasi antar budaya. Bandung: Remaja Rosdakarya.

Mubah, S.A (2011). Strategi Meningkatkan Daya Tahan Budaya Lokal dalam Menghadapi Arus Globalisasi. Vol. 24, No. 4, pp. 302-308

McClelland, D. (1988). Human motivation. New York: Cambridge University Press. 
Naim, M. (1979). Merantau: pola migrasi suku Minangkabau. Yogyakarta: Gadjah Mada University Press.

Nainggolan, T. (2012). Batak Toba di Jakarta: sejarah dan transformasi religi. Medan: Bina Media Perintis.

Nordholt, H.S. (1987). Ojo Dumeh: Kepemimpinan Lokal dalam Pembangunan. Jakarta: Sinar Harapan.

Pelly, U. (2013). Urbanisasi dan adaptasi: peranan misi budaya Minangkabau dan Mandailing di kota Medan. Medan: Unimed Press dan Casa Mesra.

Popkin, S.L. (1986). Petani Rasional. Jakarta: Yayasan Padamu Negeri.

Said, E.W. (1995). Kebudayaan dan Kekuasaan: Membongkar Mitos Hegemoni Barat. Terjemahan. Bandung: Mizan.

Sairin, S. (1991). Dimensi Kebudayaan dalam Pembangunan Pedesaan. Makalah Seminar Nasional: Optimalisasi Peran Desa sebagai Sumberdaya Potensial dalam Pembangunan Nasional. Universitas Merdeka Malang dan Depdagri, 6-7 Agustus.

Saptadi, K.Y. (2008). Membaca Globalisasi dalam Kaca Mata Perang Budaya. Makalah Seminar Globalisasi, Seni, dan Moral Bangsa, Lembaga Ilmu Pengetahuan Indonesia (LIPI) Jakarta, 25 Maret.

Sauretta, P. (2006). "You Dissin Me? Humiliation and Post 9/11 Global Politics", Review of International Studies, 32(3):495-522.

Soedjatmoko. (1987). Dimensi manusia dalam pembangunan. Jakarta: LP3ES.

Suseno, F.M. (1984). Etika Jawa: Sebuah analisa falsafati tentang kebijaksanaan hidup Jawa. Jakarta: Gramedia Pustaka Utama.

Surbakti, R. (2018). "Kelompok etnik, Desentralisasi, dan Politik Lokal di Sumatera Utara”, dalam Erond L. Damanik, Politik Lokal: Dinamika Etnisitas pada era Desentralisasi di Sumatera Utara. Medan: Simetri Institute.

Van Peursen, C.A. (1988). Strategi Kebudayaan. Yogyakarta: Kanisius

Weber, M. (2001). Etika Protestan dan Semangat Kapitalisme. Surabaya: Pustaka Promethea.

Xing, T. (2001). "The Idea of Plurality and Unity in the Configuration of the Chinese Nationality and China's Bilingual education for its ethnic minority", Chinese Education \& Society, 34(2):75-90.

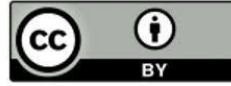

